\title{
RESPONSABILIDAD INTERNACIONAL EN LA PROPAGACIÓN DEL SARS-COV2 COMO UN HECHO INTERNACIONALMENTE ILÍCITO
}

\section{Tony Altamirano Andino ${ }^{1}$}

\section{DOI: https://doi.org/10.5377//rd.v41i1.10503}

\section{RESUMEN:}

El presente artículo científico pretende desarrollarse desde un enfoque analítico reflexivo para conocer y delimitar en base a la definición jurídica de un hecho internacionalmente ilícito, la responsabilidad internacional de organismos internacionales universales y regionales en la dispersión del Covid-19 ya sea por acción u omisión, en estricta consonancia con la implicación de colaboración inexacta por parte de China en el estudio y divulgación oportuna de las consecuencias patológicas del Síndrome Respiratorio Severo Agudo Coronavirus 2 (SARS-CoV2 por sus siglas en inglés) en el ser humano, que si bien es cierto no es un actor principal en el concierto internacional como lo son los Estados, pero que podría derivar en un hecho internacionalmente ilícito que atente contra la paz y seguridad sanitaria internacional.

Se pretende con este artículo brindarle al lector un amplio panorama jurídico internacional que no solo los Estados que componen el sistema de Naciones Unidas, tienen y poseen una responsabilidad internacional que va más allá de la primordial intención de la Carta de las Naciones Unidas de preservar la paz y seguridad internacional en cuanto a conflictos armados. Dándole una interpretación más evolucionada a este principio internacional en el tiempo actual, donde se insiste vehementemente en la transformación constante del derecho internacional a partir de los acontecimientos que están forjando el siglo XXI, ya no podemos solo interpretar que la Carta de las Naciones se refiere a una paz y seguridad internacional de conflictos armados, sino de seguridad y una paz sanitaria internacional en el mundo entero, para que futuras pandemias no paralicen la vida cotidiana de los individuos y merme las economías frágiles de los países en vías de desarrollo.

\section{PALABRAS CLAVE:}

Naciones Unidas (ONU), Carta de las Naciones Unidas, Organización Mundial de la Salud (OMS), Organización Panamericana de la Salud (OPS), SARS-CoV2, Principio de Paz y Seguridad Sanitaria Internacional.

Fecha de recepción: 29 de agosto de 2020 Fecha de aprobación:23 de noveimbre de 2020

1 Asesor y Director en Juicio, Consultorio Jurídico Gratuito, Facultad de Ciencias Jurídicas, Universidad Nacional Autónoma de Honduras (UNAH). Correo Electrónico: tony.altamirano@,unah.edu.hn 


\title{
INTERNATIONAL RESPONSIBILITY IN THE PROPAGATION OF SARS-COV2 AS AN INTERNATIONALLY WRONGFUL ACT
}

Tony Altamirano Andino

\section{DOI: $\underline{\text { https://doi.org/10.5377/Ird.v41i1.10503 }}$}

\begin{abstract}
This scientific article pretends to be developed from an analytic-reflexive perspective, to provide a broad knowledge from the point of view of the juridical definition of an internationally wrongful act, the international responsibility of universal and regional organizations in the dispersion of Covid-19, by act or omission in strict accordance with the implication of the inexact collaboration from China in the study and opportune divulgation of the pathological consequences of Severe Acute Respiratory Syndrome Coronavirus 2 (SARS-CoV2) in human beings, although it is true that individuals are not an important actor in the international concert like the different nations that compose it, but it could derive in an internationally wrongful act that attempts against the international peace and sanitary security.

It is pretended with this article to provide the reader a wide juridical international panorama that not only States that are part of United Nations have and possess the international responsibility that goes beyond the main intention of the United Nations Letter to preserve international peace and security in armed conflicts. Giving a more evolved interpretation to this international law principle in our present time, where there has being an insistent remark in the evolution of international law in the events that are constantly forging the XXI century, the United Nations Letter cannot be interpreted to refer nowadays only to peace and international security in armed conflicts, extending this principle in referring to an international peace and sanitary security worldwide, so that future pandemics will not paralyze our daily activities as individuals, and diminish the fragile economies of developing countries.
\end{abstract}

\section{KEYWORDS:}

United Nations (UN), United Nations Letter, World Health Organization (WHO), Pan-American Health Organization (PAHO), International Principle of Peace and Sanitary Security.

Date received: August 29, 2020

Approval date: November 23, 2020 2 Advisor and Director in Trial Consultorio Jurídico Gratuito, Facultad de Ciencias Jurídicas, Universidad Nacional
Autónoma de Honduras (UNAH).Email: tony.altamirano@,unah.edu.hn 


\section{INTRODUCCIÓN}

El derecho internacional clásico de relación entre Estados, ha forjado los hitos de esta rama del derecho, pero a partir de los acontecimientos históricos que están forjando el Siglo XXI, bajo una óptica analítica de la evolución acelerada del "derecho de gentes" a tal grado, que ya no solo los Estados juegan un rol preponderante en las relaciones internacionales, teniendo los organismos tanto universales como regionales, un papel predominante en el apoyo y fortalecimiento de los principios que componen el derecho internacional, aplicado en el apoyo sistemático que estas brindan a los países que realmente carecendesistemasdemocráticosyeconómicos robustos, dándose la acertada interpretación que el derecho internacional solo es para beneficio de países en vías de desarrollo, lo cual es una aseveración simplista y nefasta, siendo los mayores culpables de esto las grandes potencias que en reiteradas ocasiones solo recurren al derecho internacional para salvaguardar sus pretensiones mesiánicas en la comunidad internacional, lo cual, tienen una repercusión negativa en la responsabilidad internacional que deben asumir los organismos internacionales universales y regionales en momento de conflictos armados, pero más específicamente en tiempos de crisis sanitaria como la que actualmente vivimos, pudiendo derivarse en una responsabilidad internacional por parte de los organismos internacionales por omisión indirecta en virtud de la ineficaz o inexacta información o cooperación del Estado que tiene la obligación de brindar la información.
Esta obra no tiene como propósito una determinación inquisidora o el delimitar culpables en cuanto a la terrible propagación del SARS-CoV2 a nivel de pandemia como lo ha catalogado la Organización Mundial de la Salud (OMS). No obstante lo anterior, es menester brindar una óptica diferente al lector, y que este conozca las responsabilidades que derivan de poseer un estatus internacional como la puede y debe tener China en este debacle jurídica internacional que se pretende vislumbrar en la propagación de este virus por omisión dolosa o culposa por parte de esta potencia en brindar información al respecto, y la responsabilidad de los organismos internacionales en la efectiva colaboración de contención previa del Covid-19 en las latitudes que poseen jurisdicción o competencia, y si cabe la figura de responsabilidad por acción u omisión indirecta.

A partir de estas premisas, el objetivo central, es proporcionar y determinar la evolución dinámica y acelerada décadas tras décadas se ve reflejado en muchos principios enunciados en la Carta de las Naciones Unidas, principalmente el dinamismo ideológico que conlleva el principio de la paz y seguridad internacional que los Estados deben velar en todos sus actuaciones, pero que históricamente, este principio ha sido relacionado principalmente con conflictos armados, pero que en cierta medida vemos reflejado ciertos rasgos o comportamientos "mutatis mutandis" en el derecho internacional, pero que aún deben realizarse y luchar por modificar esos patrones de conducta que otorguen esa igualdad jurídica en el ámbito internacional para preservar el derecho humano de la salud como lo 
establece el Pacto Internacional de Derechos Económicos, Sociales y Culturales.

\section{METODOLOGÍA}

La investigación planteada, reúne las características de analítica, descriptiva y explicativa, de orden teórico, no abarcando el factor de investigación experimental. Se reputa de forma descriptiva, por cuanto se especifica y detallan 2 aspectos jurídicos internacionales quecontienenaspectosintrínsecosrelacionados en cuanto a la responsabilidad internacional de Estados y Organismos Internacionales en la propagación del SAR-CoV2, y si esta responsabilidad emana de actos constitutivos de hechos internacionalmente ilícitos que son necesarios de estudio a profundidad, y si derivan consecuencias jurídicas en contra de los actores principales en la diseminación del Covid -19 por los Estados más afectados por la pandemia. Se utiliza también la metodología analítica y explicativa por desarrollarse la evolución del principio de paz y seguridad internacional, enmarcando el mismo en el ámbito sanitario por la pandemia existente que tiene efectos directos en las grandes potencias y países en vías de desarrollo en mayor o menor magnitud.

\section{Consideraciones para la comisión de un} Hecho Internacionalmente Ilícito para deducir Responsabilidad Internacional a Estados y Organismos Internacionales.

El hecho internacionalmente ilícito como parte de la doctrina del derecho de la responsabilidad internacional, puede definirse como el comportamiento debido del sujeto en cumplir con la obligación que una norma determinada impone, por ende, existe una subordinación ya sea expresa o tácita en no adoptar comportamientos contrarios a la norma prexistente. Existe la imperante posibilidad que, por la negligencia voluntaria o involuntaria del sujeto, su conducta es interpretada como un incumplimiento de la norma a la cual se ha obligado cumplir, derivándose en una lesión o violación de esa obligación, en cuyo caso estamos ciertamente ante un hecho internacionalmente ilícito.

Por costumbre internacional, siendo esta una de las fuentes de la materia que nos ocupa, se ha tomado como primicia que solo los Estados pueden cometer hechos internacionalmente ilícitos, pero es partir del año 1944 que se produce el antecedente inmediato de imputar responsabilidad internacional a organizaciones, a partir del famoso juicio de Nuremberg (Goldensohn, Las Entrevistas de Nuremberg, 2004), en la cual se pretendía acusar a los partidarios sobrevivientes del nacionalsocialismo, por conjura a gran escala para cometer actos criminales, mediante su afiliación a ciertas organizaciones como ser el mismo Partido Nazi, la Gestapo y la Brigada de Protección, conocidos como los "camisas negras" de Himmler por sus siglas en alemán SS.

No es hasta el año 2001 que la Comisión de Derecho Internacional (CDI) sometió a la Asamblea General la aprobación del proyecto de artículos sobre la responsabilidad del Estado por hechos internacionalmente ilícitos, pero el mismo, continua a día de hoy como simple proyecto de artículos, ya que aunque el mismo concreta de manera detallada la temática, existe una elevada reserva en 
su contenido por un importante grupo de Estados, máxime potencias mundiales del calibre de Estados Unidos y la misma China que es eje central de estudio en la presente obra. Esto impone un obstáculo para que a nivel de jurisprudencia internacional se limite el poder emplear el término de responsabilidad internacional por comisión de hechos internacionalmente ilícitos, lo que al final quedó en una simple anotación del proyecto según la resolución A.G. 56/83 del 12 de diciembre de 2001, quedando únicamente la acción de comunicarlo a los gobiernos que componen la Asamblea General, estando hoy en día sin un curso o futuro cierto para su aprobación, limitando plenamente al juzgador internacional en especificar el deber de reparar sin poder utilizar el principio enunciado.

No obstante, la Asamblea General de las Naciones Unidas en su Resolución 56/82 del 2001 (Gonzalez Campos , Sanchez Rodriguez, \& Saenz de Santamaria, 2008, págs. 382-383) solicita a la Comisión de Derecho Internacional que iniciara el estudio de la responsabilidad de las Organizaciones Internacionales. Como sucedió en los juicios de Nuremberg, la Comisión de Derecho Internacional, denotó 2 situaciones particulares para poder establecer la responsabilidad de Organizaciones Internacionales por hechos internacionalmente ilícitos, como ser la imputación directa únicamente a la parte directiva de la Organización, a la totalidad de sus Estados miembros o solo a una parte. El segundo escenario se desarrolló en aplicación de los criterios de responsabilidad por riesgo o por actos no prohibidos por el Derecho Internacional.
El primer escenario se vincula con las acciones derivadas a poder determinar la comisión de hechos internacionalmente ilícitos contra los Estados de una organización internacional, tomando en cuenta el grado de participación o colaboración en la constitución del mismo, tomando en consideración el nivel de los miembros que toman decisiones en la organización, así como la responsabilidad de otros miembros que brindaron apoyo a los Estados que emiten decisiones o resoluciones, particularidades que dificultan el poder delimitar objetivamente la responsabilidad internacional por algún hecho internacionalmente ilícito cometido.

El segundo escenario se desarrolla en la problemática de la interpretación del término riesgo. Donde se encuentra la regulación del riesgo, ya que el mismo a ser extremadamente amplio, otorgando un valor de subjetividad para concretar la existencia de una situación de riesgo internacional. Por ejemplo, como pudo preverse la propagación del SARS-CoV2 como un riesgo a escala internacional, siendo que el riesgo de propagación no era conocido por la Organización Mundial de la Salud ya que el último registro de una pandemia en la historia de vida de la OMS data del año 1981 con el Sida, 1968 con la Gripe de Hong Kong y en 1957 con la Gripe Asiática. (National Geographic, s.f.) Si se valora en términos de rango entre los años de cada pandemia, el patrón es de 11 años, 13 años, y 39 años respectivamente, por ende, como catalogar o definir la responsabilidad por riesgo, ya que por intervalo de años, no puede establecerse un criterio mínimo para la aparición de nuevas pandemias, ni mucho menos por el intervalo de las epidemias que han existido 
a través de la historia de vida la OMS, por ende, el criterio de responsabilidad por riesgo, presenta vastas complicaciones para imputar una responsabilidad internacional.

Existe además de los criterios enunciados para poder establecer o determinar un hecho internacionalmente ilícito, el elemento temporal de la obligación violada. Existen tratadistas internacionales, y la misma Comisión de Derecho Internacional, que concluyen que el hecho internacionalmente ilícito se deriva de la violación de una obligación internacional y no directamente de una norma emanada de un tratado o cualquier otro cuerpo legal de naturaleza internacional, entendiéndose que la obligación internacional es más amplia en cuanto a la violación simplemente de la norma, lo cual, al emplearse la violación de una norma como un hecho internacionalmente ilícito, se está dejando por fuera las ramificaciones de obligaciones que emanan del cumplimiento de la interpretación subjetiva de la norma, entendiéndose que la comisión quiso otorgar a esta regla un sentido más objetivo en tanto que la norma puede interpretarse desde una óptica jurídica subjetiva, mientras que la obligación internacional puede verse e interpretarse desde la objetividad por su naturaleza amplia para abarca muchos aspectos que la norma puede dejar por fuera.

Al determinar la obligación violada, el elemento temporal cobra suma importancia en la determinación de esta, ya que debe analizarse de manera directa si la violación de la obligación internacional es instantánea, dicho en otras palabras, que sus efectos son apreciables en un determinado momento, o, por otro lado, si esta violación persiste o se distribuye a lo largo de un período de tiempo duradero.

La temporalidad de la violación de una obligación contiene 2 interrogantes principales que se debe concretizar para poder catalogar un hecho internacionalmente ilícito, siendo el primero, el momento temporal donde se encuentran reunidos todos los elementos constitutivos de la violación, y la segunda sería, el período entero durante el cual la violación se desarrolla, es decir, desde cuándo y hasta cuando se extiende su período de perpetración, y esto tanto antes como después del momento en que consta su existencia. (Gonzalez Campos, Sanchez Rodriguez, \& Saenz de Santamaria, 2008, pág. 397).

$\mathrm{Si}$ aplicamos la temporalidad de la obligación violada por parte de China en brindar la información sobre el SARS-CoV 2, y la OMS/OPS de divulgarla, al analizar el génesis del virus en algunos hechos en el seguimiento al desarrollo de la enfermedad, en el informe recibido por parte de China el 3 de enero del 2020 (OMS, s.f.), únicamente detalla sobre una neumonía vírica de origen desconocido que ha comenzado en la ciudad de Wuhan. El 14 de enero 2020, aun no se tiene información según las declaraciones de la OMS vía Twitter, que no hay pruebas claras que su transmisión sea entre seres humanos. El 16 de enero 2020, la Organización Panamericana de la Salud, emite su primera alerta epidemiológica sobre el coronavirus, y el 20-21 de enero del 2020, se lleva a cabo por parte de la OMS la primera misión a Wuhan. El 22 de enero 2020, la OMS informa que las investigaciones apuntan a una transmisión entre seres humanos. 
Al analizar el primer escenario para determinar el momento temporal donde se encuentran todos los elementos constitutivos de la violación, podríamos delimitar que fue en la misión realizada por la OMS el 20-21 de enero del 2020, en donde no se sabe con exactitud, y es una de las acérrimas críticas del Presidente Estadounidense Donald Trump (British Broadcasting Company, s.f.) acusar al Estado Chino de tener un control absoluto de la OMS, por haber engañado al mundo mediante la información brindada por la OMS sobre el virus, delimitando específicamente en esa línea temporal, si el gobierno chino conocía o no los alcances del virus, o si realmente se ocultó información a la OMS por parte de China, o la OMS en realidad tuvo la información y fue influenciada por esta potencia mundial en no divulgar verazmente la información. Por las acciones emprendidas por la OMS en los meses venideros, es comprobable que se realizaron las acciones dentro de los límites que tiene esta organización internacional, de informar y activar los protocolos para poder investigar a fondo los efectos del virus, por ende, la responsabilidad por la regla de temporalidad, no podría ser aplicada a priori a la OMS.

$\mathrm{Al}$ abordar este punto, se incursiona en el segundo criterio del principio de temporalidad de violación de la obligación en cuanto al período entero durante el cual la violación se desarrolla, es decir, desde cuándo y hasta cuando se extiende su período de perpetración. Se determina que la violación continúa a día de hoy por la supuesta desinformación por parte de China a la OMS por las consecuencias del SARS-CoV2 en todo el mundo, a casi 8 meses desde el surgimiento del virus, pero esta primicia es imputable al supuesto Estado infractor y no a la organización internacional en sí.

Ante las afirmaciones desarrolladas, cabe la interpretación que puede existir responsabilidad internacional de China por violación a la obligación de información veraz y exacta sobre las condiciones patológicas del virus, como un hecho internacionalmente ilícito, no así la OMS/OPS teniendo en cuenta los criterios de la CDI para la comisión de hechos internacionalmente ilícitos por organismos internacionales, por no poderse imputar directamente a la parte directiva de la Organización, como lo es el Director Ejecutivo de la OMS o a la totalidad de sus Estados miembros o solo a una parte que forman la Asamblea General de la OMS como su órgano supremo de decisión, ni tampoco es aplicable el criterio de responsabilidad por riesgo o por actos no prohibidos por el Derecho Internacional.

Al poder delimitar en ciertos aspectos que los organismos internacionales no son afectos a la responsabilidad internacional por hechos internacionalmente ilícitos, el foco de discusión retorna a Beijing, retomando la posibilidad de una responsabilidad internacional por parte de China Popular en la propagación del SARS-CoV2 tomando en cuenta la hipótesis de la temporalidad de la obligación violada por el Estado chino al "ignorar sus obligaciones de informar" como lo exclamó el Presidente Trump en el mes de mayo 2020 sobre el Covid - 19.

Si bien es cierto la obligación violada es concretamente la de informar, pero al ser una 
obligación no contemplada en la norma, su amplitud de interpretación bastaría decir es suficiente la que realizó China el 3 de enero del 2020. Se estima que si bien es cierto la norma no detalla una definición exacta de la obligación de informar, pero al ser los principios generales del derecho una de las fuentes del derecho internacional, el cual determina que el accionar y presumir los actos realizados por los individuos y concretamente de los Estados, son de buena fe, sin embargo, para el análisis jurídico-reflexivo que se pretende demostrar al lector, este principio es interpretable en ambas vías, tanto de informar de buena fe todo lo concerniente al virus por parte de China, pero también, se aplica en sentido favorable a Beijing en cuanto que su obligación de informar el 3 de enero y el 20 y 21 de enero 2020 fueron de buena fe sin dejar ninguna información por fuera, o el ocultar información.

\section{Aplicabilidad del Principio de Paz y Seguridad Internacional en el ámbito Sanitario.}

El artículo 1 de la Carta de las Naciones Unidas es el que establece el propósito primordialdelas Naciones Unidas, considerado el principio universal que rige las relaciones internacionales y la regulación jurídica internacional como es el de "mantener la pazy la seguridad internacional, y con tal fin; tomar medidas colectivas eficaces para prevenir y eliminar amenazas a la paz, y para suprimir actos de agresión u otros quebrantamientos de la paz; y lograr por medios pacíficos, $y$ de conformidad con los principios de la justicia y del derecho internacional, el ajuste o arreglo de controversias o situaciones internacionales susceptibles de conducir a quebrantamientos de la paz;" (Lopez Martín \& Carnerero Castilla, 2008)

Al definir el concepto de paz y seguridad internacional, es apreciable que la amplitud de la definición, se interpreta en el sentido extenso de poder prevenir y erradicar cualquier acto que implique el quebrantamiento de la paz, ya sea por simples amenazas a la paz, pero también abarca para todo tipo de actos, sucesos o situaciones que impliquen el perturbar la paz internacional de los países que conforman el concierto internacional.

La Carta de la ONU al ser propiamente adoptado en el año de 1945 año que finaliza la segunda guerra mundial, la intención de los legisladores al momento de aprobar la Carta, es prevenir futuros conflictos armados que pudieran tener igual o mayor impacto global como la gran guerra, pero de manera muy acertada, dejan una amplitud en el principio de la paz y seguridad internacional, y un año más tarde a partir del 22 de julio de 1946, se crea la Organización Mundial de la Salud (OMS), mediante la constitución de este organismo internacional encargada de velar por la salud de todos los pueblos como una condición fundamental para lograr la paz y la seguridad, dependiendo de la más amplia cooperación de las personas y de los Estados. (Organización Mundial de la Salud, s.f.)

La comunidad internacional entendió en la Conferencia Sanitaria Internacional que la desigualdad de diversos países en lo relativo al fomento de la salud y control de las enfermedades, sobre todo las transmisibles, constituyen un peligro común, que atenta 
contra la paz y la seguridad sanitaria internacional promulgada en esta conferencia que le da vida a la Organización Mundial de la Salud. Las potencias vencedora en la II Guerra Mundial, y que también habían experimentado la también cruenta I Guerra Mundial, que ya al ocaso de esta guerra se dio la pandemia de la gripe española, y al comprobar las atrocidades biológicas con el Gas Zyklon-B y sanitarias (Tifus) perpetrados por Hitler (Goldensohn, Rudolf Hoss, 2004), comprendieron que debía prevenirse $\mathrm{y}$ erradicarse cualquier comportamiento ya sea bélico o en el ámbito sanitario que pudiese perturbar la paz y seguridad en el ámbito sanitario, y que no tuviera repercusiones a nivel global.

Es con el Pacto Internacional de Derechos Económicos, Sociales y Culturales del 16 de diciembre de 1966, 11 años después de la pandemia de la Gripe Asiática, se considera imperativo incorporar en un instrumento internacional, una ampliación a la obligación de los Estados por velar por la paz y seguridad sanitaria internacional. Es en el artículo 12 de este Pacto el cual establece que "los Estados Partes en el presente pacto reconocen el derecho de toda persona al disfrute del más alto nivel posible de salud física y mental. Entre las medidas que deberán adoptar los Estados Partes en el Pacto, a fin de asegurar la plena efectividad de este derecho figurarán las necesarias para: a) La reducción de la mortinatalidad y de la mortalidad infantil y el sano desarrollo de los niños. b) El mejoramiento en todos sus aspectos de la higiene del trabajo y la del medio ambiente. c) La prevención y el tratamiento de las enfermedades epidémicas, endémicas, profesionales y de otra índole y la lucha contra ellas. d) La creación de condiciones que aseguren a todos asistencia médica y servicios médicos en caso de enfermedad.

Sobresale el literal "c" del artículo 12 de este instrumento internacional, el cual ya determina de forma más precisa y detallada en cuanto a las condiciones mínimas que debe regir el sistema sanitario internacional para la erradicación de las enfermedades epidémicas, endémicas, y profesionales, abarcando a las pandemias cuando el artículo menciona cualquiera de otra índole. Pero al ver los demás artículos del Pacto, vemos que únicamente en este artículo se refleja el derecho y obligación de los Estados en velar por una paz y seguridad sanitaria internacional, que, en conjunto con las labores y principios rectores de la OMS, el principio internacional por excelencia, y rector de las relaciones entre los sujetos del derecho internacional, es aplicable y abarca en toda la temática sanitaria.

Lo anteriormente aseverado es aplicable especialmente en este momento de crisis sanitaria internacional con el Covid-19, el cual, es entendido que la pandemia no solo dejará aspectos nuevos en la medicina, pero también en el aspecto jurídico internacional, ya que el dinamismo con el que cuenta el derecho de gentes, que se transforma y adapta a las situaciones de la vida cotidiana de los Estados, aunando cada acontecimiento de impacto global que trastoca e innova en cada aspecto del derecho internacional, teniendo como causalidad directa el enriquecer cada una de las fuentes de esta rama jurídica, que se ha venido desarrollando desde la creación de la carta de las Naciones Unidas, los juicios 
de Nuremberg, nacimiento de la OMS, hasta la actual pandemia.

\section{Posibilidad de Acusación Internacional por Propagación del SARS-COV 2 a China y la Organización Mundial de la Salud.}

Múltiples interrogantes surgen al momento de hablar sobre una responsabilidad internacional de China en la propagación del SARS-CoV2, que lamentablemente ha dejado secuelas imborrables en muchos países no solo a nivel sanitario, con el colapso de muchos sistemas internos de salud, pero existe la innegable repercusión económica que ha producido una contracción económica inmensa en las grandes economías mundiales, y en una escala preocupante, en países en vías de desarrollo, los cuales tendrán serias repercusiones en cuanto a índices de pobreza, crecimiento económica y corrupción.

Luego de ver las múltiples consecuencias en el mundo por el Covid-19, surge la interrogante, quien es el culpable y que mecanismos jurídicos existen para poder imputar al causante de todas estas repercusiones negativas. Muchos expertos en derecho internacional coinciden en base a la legislación internacional vigente que solo la República Popular de China es a la única que puede ser objeto de reclamación alguna por parte de cualquier Estado que ha sufrido los embates del SARS-CoV2, ya que como se ha demostrado en el presente artículo, existe una alta complejidad en poder imputar responsabilidad internacional a la OMS. Al ser viable únicamente una reclamación entre Estados, el único escenario posible en el ámbito internacional es la Corte Internacional de Justicia.
Si bien es cierto, se acusa a Beijing de no informar a tiempo, el portal de la OMS determina que China informó en su debido momento a la OMS sobre el brote del Covid 19 como se ilustró en el acápite primero de este ensayo, pero si es más concreto determinar que la información pudo no ser la más exacta ni veraz lo cual muchos gobiernos y potencias mundiales imputan a China.

Cualquiera de estas potencias o Estados directamente agraviados por esta situación, puede invocar el artículo 75 (Anadolu, s.f.) de la Constitución de Organización de la OMS, el cual detalla lo siguiente: "Toda divergencia o disputa respecto a la interpretación o aplicación de esta Constitución que no sea resuelta por negociaciones o por la Asamblea de la Salud, será sometido a la Corte Internacional de Justicia de conformidad con el Estatuto de la Corte, a menos que las partes interesadas acuerden otro medio de solucionarla."

En los artículos 61 al 65 de la Constitución de la OMS solo se refiere a la obligación de los Estados en informar a la organización cualquier situación epidemiológica que este sucediendo en sus territorios. No existiría una violación a la normativa internacional, por parte de China en virtud de haber cumplido el requisito mínimo para no podérsele imputar una responsabilidad internacional. La falta de información por desconocimiento de las patologías del virus tampoco implica una responsabilidad a China, únicamente estaríamos ante el escenario de una posible disputa ante la Corte Internacional de Justicia si se comprueba el ocultamiento de información vital sobre el virus, ya que si 
existiría una violación al principio de la paz y seguridad sanitaria internacional por omisión como lo establece el artículo 1 de la Carta de las Naciones Unidas, ya que esa omisión limitó ampliamente el accionar de la OMS según su principio rector sobre el mantenimiento de la salud de los todos los pueblos.

Para que exista un mantenimiento eficaz de la seguridad sanitaria internacional, esto implica que debe existir un esfuerzo en conjunto de la OMS con los países miembros de la organización, para que estos apliquen mecanismos estatales efectivos; en esto, nos referimos a China y a su población explícitamente en la ciudad de Wuhan; para lograr la paz y la seguridad sanitaria, donde de comprobarse el ocultamiento de información, China incurrió en una violación al artículo 12 literal "c" del Pacto Internacional de Derechos Económicas, Sociales y Culturales, dando lugar a esa omisión de proporcionar información a la OMS, una violación al artículo 65 de la Constitución de la OMS por la insalubridad de los mercados en Wuhan, cuna del SARS-CoV2.

La posibilidad de cualquier Estado en entablar una reclamación ante la Corte Internacional parece poco probable, pero existe otra problemática jurídica para poder entablar la causa contra China, siendo la que Beijing no acepta la jurisdicción obligatoria (Justice, s.f.) de la Corte, ya que si bien es cierto es miembro fundador de la Naciones Unidas, y miembro permanente del Consejo de Seguridad de la ONU con derecho a veto, no reconoce la jurisdicción de la corte de forma obligatoria, ya que desde el momento que existen fallos en contra de cualquier Estado, especialmente contra países denominados potencias mundiales, su accionar es el de retirar su declaración de jurisdicción obligatoria de la corte como ya ha pasado con Estados Unidos cuando fue condenado en la reclamación de actos paramilitares en Nicaragua, haciendo China lo mismo al ser condenada en el año 2016 por una reclamación formulada por Filipinas ante la Corte Internacional de Justicia.

Ante todo esto, cabe mencionar que existe una complejidad extensa para que cualquier país determine en primer lugar, entablar una reclamación ante la Corte Internacional de Justicia contra la República Popular de China, por ser esta una de las potencias mundiales que rige su propio destino en el ámbito internacional, velando por cumplir un rol engañoso que puede interpretarse como un acatamiento parcial al derecho internacional, al proponer la reparación del daño con la distribución gratuita al mundo de la vacuna (Deutsche Welle, s.f.) contra el SARS-CoV2, así como contribuir con un mayor aporte económico a la OMS, como contrapeso a la decisión de Estados Unidos en retirar el apoyo económico a la organización.

China al ver sus intereses trastocados por un posible fallo en su contra por un tribunal internacional, la visión negativa que es palpable a nivel mundial por la irresponsabilidad sanitaria que existe en ciertas localidades del gigante asiático, es propio concluir que no existe la voluntad de respetar la jurisdicción de la Corte Internacional de Justicia que pudiese menoscabar su reputación y rol hegemónico como la potencia que brinda equilibrio internacional al rol de Estados Unidos en el mundo, pero que al querer afirmar "China 
nos vemos en la corte" (Ius Et Veritas, s.f.) por lo acontecido por el Covid-19, en esto, todavía, el derecho internacional no posee los mecanismos jurídicos para esta situación en concreto, recurriendo en el mejor de los casos en consolidar los mecanismos pacíficos para la solución de conflictos, siendo la Corte Internacional en este caso, una instancia "ultima ratio".

\section{CONCLUSIONES}

- El derecho internacional se refiere al hecho internacionalmente ilícito como una figura doctrinal más que a una figura jurisprudencial en virtud del proyecto encomendado a la Comisión de Derecho Internacional que no ha podido constituirse como un cuerpo jurídico validado por la Asamblea General de la ONU, debido a la escasa voluntad de los miembros de Naciones Unidas en constreñirse a una norma internacional que conlleva más obligaciones que beneficios en el plano internacional.

- En cuanto a los criterios de responsabilidad internacional por comisión de hechos internacionalmente ilícitos por organismos internacionales, continua teniendo diversas aristas para poder ser empleado en el concierto internacional, limitándose la responsabilidad internacional a los Estados, siendo dificultoso poder delimitar bajo los criterios de la CDI, imputar un hecho internacionalmente ilícito a un organismo universal o regional, no pudiéndose responsabilizar a la OMS/OPS la propagación del SARS-CoV2.
- Los antecedentes históricos en cuanto a la imputación de responsabilidad internacional por hechos internacionalmente ilícitos a organizaciones como lo fue el juicio de Nuremberg, y el Proyecto de Artículos de la CDI, la implementación del principio de paz y seguridad internacional en el ámbito sanitario, que es aplicable a partir de la creación de la OMS, denota una adaptación del derecho internacional para configurar su doctrina atendiendo cada acontecimiento de alto impacto a nivel global.

- La reparación efectiva del daño como lo ha contemplado la Corte Internacional de Justicia en muchos de sus fallos, pero sin utilizar el término de hecho internacionalmente ilícito, fomenta en gran medida que muchas naciones hayan retirado su aceptación a la jurisdicción obligatoria de la corte para obviar la responsabilidad de la reparación efectiva del daño impuesto por la corte, para realizar esta reparación efectiva por la apreciación subjetiva del país infractor en cuanto a la magnitud del daño causado. 


\section{BIBLIOGRAFÍA}

Anadolu, A. (s.f.). Agencia Anadolu. Obtenido de https://www.aa.com.tr/es/ mundo/expertos-en-derecho-internacionalculpan-a-china-por-da $\%$ C $3 \%$ B 1 oscausados-por-el-coronavirus11812288\#: : :text=Aunque $\% 20 \mathrm{el} \% 20$ Consejo\%20de\%20Seguridad, con $\% 20$ derechos $\% 20$ de $\% 20$ veto $\% 2 \mathrm{C} \% 20$ dijo.\&text $=$ Seg $\%$ C 3\% B A n $\% 20$ Kao\%2C\%20el $\% 20 \% \mathrm{C} 3 \% \mathrm{BA}$

British Broadcasting Company. (s.f.). BBC. Obtenido de https://www.bbc.com/mundo/ noticias-internacional-52857060

Goldensohn, L. (2004). Las Entrevistas de Nuremberg. (R. Gellately, Ed.) Torrelaguna, madrid: Santillana Ediciones Generales.

Goldensohn, L. (2004). Las Entrevistas de Nuremberg. (R. Gellately, Ed.) Madrid: Santillana.

Gonzalez Campos , J. D., Sanchez Rodriguez, L. I., \& Saenz de Santamaria, P. A. (2008). Curso de Derecho Internacional Público. Navarra: Editorial Aranzadi.

Justice, I. C. (s.f.). International Court of Justice. Obtenido de https://www.icj-cij. org/en/declarations

Lopez Martín, A. G., \& Carnerero Castilla, R. (2008). Textos de Derecho Internacional Público. Madrid: Iustel.
National Geographic. (s.f.). Obtenido de https://historia.nationalgeographic.com. es/a/grandes-pandemias-historia 15178/4

OMS. (s.f.). Organización Mundial de la Salud. Obtenido de https://www.who. int/es/news-room/detail/29-06-2020covidtimeline

Organización Mundial de la Salud. (s.f.). OMS. Obtenido de https://www.who. int/governance/eb/who constitution sp.pdf?ua $=1$

Veritas, I. E. (s.f.). Ius 360. Obtenido de https://ius360.com/otro/internacional/nosvemos-en-la-corte-sobre-la-viabilidadde-someter-a-china-ante-la-corteinternacional-de-justicia-a-proposito-dela-pandemia-de-la-covid-19-ana-vergara/

Welle, D. (s.f.). Deutsche Welle. Obtenido de_https://www.dw.com/es/china-prometecompartir-la-vacuna-y-acepta-unainvestigaci\%C3\%B3n-cuando-pase-lapandemia/a-53486822 